\title{
Teachers' Experiences of a Professional Development Program for Differentiated Instruction
}

\author{
Anastasia Mavidou, Domna Kakana \\ School of Early Childhood Education, Aristotle University of Thessaloniki, Thessaloniki, Greece \\ Email: anmavido@gmail.com,dkakana@gmail.com
}

How to cite this paper: Mavidou, A., \& Kakana, D. (2019). Teachers' Experiences of a Professional Development Program for Differentiated Instruction. Creative Education, 10, 555-569.

https://doi.org/10.4236/ce.2019.103040

Received: February 12, 2019

Accepted: March 4, 2019

Published: March 7, 2019

Copyright $\odot 2019$ by author(s) and Scientific Research Publishing Inc. This work is licensed under the Creative Commons Attribution International License (CC BY 4.0).

http://creativecommons.org/licenses/by/4.0/

\begin{abstract}
Differentiated Instruction (DI) is considered as the teaching approach that builds upon children's differences in order to address them and consequently lead each and every child to academic success. Although DI seems to be an effective teaching approach, teachers' perceptions and/or misconceptions, as well as unsuccessful attempts of implementation, constrain its inclusion in everyday practice. Therefore, the need for appropriate and effective Professional Development programs (PDp) is emerging in order to clearly define the concept of DI and facilitate the application of related practices. The aim of the current study is to shed light onto teachers' experiences with DI, through a PDp, which was developed to provide effective support to teachers to change their perceptions and teaching practices and apply successfully DI. The participants were 7 in-service kindergarten teachers. The program lasted 8 months and included deepening on theoretical and practical levels. Multiple tools were used for data collection, such as open-ended questionnaires, personal diary of the researcher and individual semi-structured interviews. Content Analysis showed that teachers initially had misconceptions about the concept of DI and doubts regarding its applicability, while during the program they realized its positive impact on children, which encouraged them to continue their differentiating practice. According to teachers, the successful elements of the program, which contributed to the revision of their personal theories and generally their professional development, were the cooperation with colleagues in a warm and welcoming climate during the meetings, the long-lasting duration and the constant feedback and reflection. To conclude, the PDps provide the necessary context for the teacher to experiment with DI, though the prediction of future application is not yet sufficiently studied.
\end{abstract}

\section{Keywords}

Differentiated Instruction, Professional Development, Teacher Education, 
In-Service Teachers, Kindergarten

\section{Introduction}

It is common sense that children differ one from another. Teachers observe different readiness levels, needs, backgrounds, learning styles and interests among children in the same classroom (Tomlinson, Brighton, Hertbert, Callahan, Moon, Brimijoin et al., 2003). In fact, more differences are expected to be added, as financial crisis, immigration, learning difficulties and other factors affect the composition of students in a classroom and their achievement (Smit \& Humpert, 2012; Suprayogi, Vackle, \& Godwin, 2017). For example, the financial crisis may affect the access of children in knowledge, as families may limit their expenses to basic needs.

Differentiated Instruction (DI) is an innovative teaching approach which takes under consideration the existing variations among children to design teaching and learning responding to the needs of all (Tomlinson, 2001). However, the application of the approach is restrained (Cha \& Ahn, 2014; Ruys, Defruyt, Rots, \& Aelterman, 2013; Wan, 2017), due to teachers' deficit of knowledge and skills to differentiate their instruction sufficiently and effectively (Suprayogi, Vackle, \& Godwin, 2017; Tobin \& McInnes, 2008).

Apparently, the gap of empirical studies about DI implementations (Hall, 2002; Santamaria, 2009; Smit \& Humpert, 2012), along with the lack of definitions about how-to-differentiate (Tobin \& McInnes, 2008), contributes to the teachers' confusion about the concept of DI (Hall, 2002; Santamaria, 2009). Thus, a deep understanding of DI's theoretical background is essential to precede the application of the new approach. Therefore, Professional Development programs (PDp) are necessary when studying DI's application, as such programs are able to provide additional definitions and support (Mills, Monk, Keddie, Renshaw, Christie, Geelan et al., 2014).

This study focuses on the kindergarten teachers' side, during their experience in participating in a PDp for DI, revealing their personal and professional development through understanding, applying and reflecting on DI practices.

\section{Theoretical Framework}

\subsection{Differentiated Instruction}

The educational systems worldwide are based on the general assumption that children from the same age have similar learning needs. However, the age cannot ensure the absence of any differences in interests, motivations, backgrounds and abilities (Bostina-Bratu \& Negoescu, 2016). Such differences are often ignored, as teaching to the middle level of the classroom is the common practice (Tomlinson, 1999). Subsequently, the advanced learners are not challenged enough, while at the same time the struggling ones are over-challenged and fi- 
nally remain puzzled (Koeze, 2007), proving that one-size-fits-all approach of instruction is not effective.

DI is a teaching approach that aims to close possible gaps between high and low achievers and, hence, decrease the school failure (Tobin \& Tippett, 2014) by providing an educational context where every difference is honored and welcomed (Bostina-Bratu \& Negoescu, 2016). According to Hall (2002), DI is a combination of multiple effective educational theories and practices. Indeed, DI is not considered as merely one strategy, but as a teaching approach that embodies many strategies (Watts-Taffe, Laster, Broach, Marinak, McDonald-Connor, \& Walker-Dalhouse, 2012), since it addresses a range of children's differences on several levels and based on various characteristics (Heacox, 2002).

As a result, the starting point of instruction is corresponding to the child's level of readiness, interests and learning style (Tomlinson, 1999). The teacher who differentiates his/her instruction doesn't expect learners to find the way to adjust to his/her instruction, but proactively tailors the teaching and learning process according to them (Gregory \& Chapman, 2007; Faber, Glas \& Visscher, 2018). Moreover, the lesson integrates a variety of sources, materials and assignments in different difficulty levels, provides different levels of support and multiple arrangements of the classroom. To that end, instruction is challenging, interesting and developmentally appropriate (Taylor, 2015). The learning goals are achieved through different learning paths (Tobin \& McInnes, 2008), as DI incorporates various and flexible ways of presentation, expression and selection of learners' engagement in the learning process (Tobin \& Tippet, 2014).

Since the main aim of DI is to increase the academic success of children, its impact on achievement has been the object of investigation for several researchers. Recent studies suggest that differentiated approach affected positively children's performance and enhanced motivation for learning (Koeze, 2007; Lewis \& Batts 2005; Little, McCoach, \& Reis, 2014; Tobin \& Mc Innes, 2008; Tomlinson \& McTighe, 2004). Most empirical studies focused on the effectiveness in reading (Little, McCoach, \& Reis, 2014) and mathematics (Scott 2012; Tieso, 2005), while few evaluated differentiation in other fields, such as science education (Odgers, Symons, \& Mitchell, 2000).

Although, DI is considered as an effective and promising teaching and learning approach that should be included in teachers' everyday practice, the related literature indicates that teachers tend to avoid DI's application (Mills et al., 2014; Wan, 2017; Suprayogi, Vackle, \& Godwin, 2017; Tobin \& Tippett, 2014; Tomlinson et al., 2003), as they perceive differentiation as a difficult and time-consuming procedure (Danzi, Reul, \& Smith, 2008). Furthermore, in the study of Mills et al. (2014), teachers confused DI with individualized instruction and believed they had to prepare as many activities as the students in their classroom. In addition, evaluation of children's initial ideas and abilities did not precede the decisions regarding the grouping arrangements, along with the application of flexible grouping, so the differentiation was at least defective. Another common misconception that is greatly reported is the tendency to sideline the needs of 
advanced learners and provide more support to those who have difficulties in achieving their learning goals (Scott, 2012; Wan, 2017). This misconception reveals that teachers hold a fixed mindset about a child's readiness level, according to which the ability is something solid and crosses all the subjects, while flexible grouping is based on a growth mindset that acknowledges the strengths and weaknesses of a learner (Dweck, 2006). As a matter of fact, flexible grouping is usually replaced by whole-class instruction (Smit \& Humpert, 2012).

The systematic evaluation of children is perceived as a constraint by teachers (Mills et al., 2014; Smit \& Humpert, 2012; Tobin \& Tippett, 2014), due to their difficulty to manage appropriately the collected information (Cha \& Ahn, 2014). Evaluation and DI are interdepended concepts, as no differentiation can really occur without knowing deeply the learners and the needs that instruction will respond to (Tomlinson \& Moon, 2013). Additionally, teachers argue that DI is undermined due to the big number of students in their classroom and the time-consuming nature of preparation for differentiation (Wan, 2017).

Indeed, teachers from Wan's (2017) study preferred to differentiate instruction from a more teacher-centered approach rather than child-centered, because it required less time of preparation. Similarly, other researchers (Casey \& Gable, 2012) discovered that teachers were more familiar with the more superficial differentiation strategies, such as providing options, rather than more sophisticated differentiation, like tiered activities (Koeze, 2007).

Apparently, the application of DI is evasive for teachers, maybe because it requires a change in their teaching and learning philosophy (Tobin \& Tippett, 2014). To this end, appropriate training programs seem to be the only way to provide additional definition of DI and support to teachers (Gregory \& Chapman, 2007).

\subsection{Professional Development Programs for Differentiated Instruction}

Currently, more and more researchers aim in the professional development of pre- and in-service teachers to assist them include DI strategies in their teaching repertoire, indicating that participation in a $\mathrm{PDp}$ impacts positively the application of DI (Burkett, 2013; Wu \& Chang, 2015). For example, Tobin \& McInnes (2008) organized a PDp for DI with 10 teachers participating for 5 months in order to assist them manage the differences that stem from readiness levels. Until the end of the program the participants acquired material and strategies to respond to the reading needs of their students. Little, McCoach, \& Reis (2014) also organized a PDp with constant group meetings of teachers in order to familiarize them with the differentiated concept and provide additional support during the implementation. Similarly, Tobin \& Tippett (2014) developed a PDp with 5 teachers, including group meetings where teachers engaged in a variety of presentations, short lectures, activities and discussions about DI. The teachers referred that due to the program their instruction was oriented even more to students than merely to the curriculum, thus making it more child-centered. 
Although PDps may positively affect the teaching practices, DI is a complicating approach that targets high effectiveness. There are several characteristics of PDps that are proven effective in changing the perceptions and practices of teachers. Hunzicker (2011) and Timperley (2008) argue that PDp's effectiveness increases when it considers the existing perceptions and needs of participants. Accordingly, the investigation of the teachers' initial ideas is necessary in order to design appropriately the content of the program. Moreover, a context with cooperation (Chitanana, 2012; Parsad, Lewis, Farris, \& Greene, 2001) and interaction with colleagues is essential to allow teachers share their experiences and ideas (Cha \& Ahn, 2014; Chen \& McCray, 2012; Smit \& Humpert, 2012).

Another crucial element for any PDp is the chance to apply in the classroom the new ideas discussed during the meetings (Vasumathi, 2010), and then return to the group and share the new experiences in order to get feedback and reflect (Phillips \& Weingarten, 2013). Indeed, the reflection should emphasize on the impact of a teacher's action on the learner, and more specifically, how different groups of children react (Timperley, 2008; Vasumathi, 2010). This constant circle of action and reflection provides the appropriate support to teachers to take the risk of experimenting with new approaches and ideas and finally, enrich their teaching repertoire (Hunzicker, 2011).

Additionally, authenticity is important for PDp, since the content is adjusted according to real needs, practices and data from the classroom of each participating teacher (Chitanana, 2012), thus relating the teacher's practice with the new concepts and/or approaches. Such a process naturally needs to last for a long period of time in order to be successful (Hunzicker, 2011).

Obviously, the investigation of PDp's impact on the application of DI is quite limited (Wan, 2017), and therefore more research is necessary. Additionally, many PDps had short-lasting applications and concentrated mainly to teachers from elementary to university levels of education, leaving behind kindergarten teachers. Nonetheless, the philosophy of early childhood education, as well as the diversity of kindergarten classroom (Wu \& Chang, 2015), is aligned with differentiation (Brennan, 2008; DeBaryshe, Gorecki, \& Mishima-Young, 2009).

In this study, a long-lasting PDp was designed and implemented in order to support kindergarten teachers to deepen in DI, change their perceptions and include the approach in their practice. The main research aim was to evaluate the effectiveness of the program through the experiences of the participating teachers. Specifically, we sought to answer what kind of experiences the teachers had, what progress they followed, which elements of the PDp were evaluated as good experiences by them and which were the referred setbacks of the program.

\section{Method}

\subsection{Participants}

The participants of the study were 7 kindergarten teachers corresponding to 7 kindergarten schools. 3 of the schools were located at urban and 4 of them at 
sub-urban regions of Magnesia, Central Greece. The teachers were females, quite experienced, as they had been working for 11 to 17 years $(M=15.3, S D=2.2)$ and had high educational qualifications: 2 teachers with bachelor degrees, 4 with a master's degree and 1 with a $\mathrm{PhD}$ title.

Convenience sampling was followed, since the group of teachers was formed due to their interest in DI, along with their willingness and openness to change their instructional practice. Therefore, the selection of the kindergarten schools was based on the consent of the teachers to participate in the study.

\subsection{Roles}

Aside of the teachers, a facilitator and a supervisor participated in the PDp. Apparently, each type of participant had a distinct role. In particular, teachers were expected to collect data from children through systematic observation, cooperate with the facilitator in designing the instructional plans, apply differentiated interventions in their classroom, share their ideas and experiences, and finally, reflect on their action.

The facilitator ( $1^{\text {st }}$ author) prepared, organized and managed the meeting conversations, provided teachers with the appropriate tools (e.g. for observations), cooperated with both the teachers and the supervisor to design and differentiate the instructional plans, had individual meetings with teachers and, more importantly, encouraged the teachers to continue through the difficult process of changing their practice.

Last but not least, the supervisor ( $2^{\text {nd }}$ author) invited and formed the group of teachers and supervised the whole process of the program, as she provided consultancy and useful guidelines on scientific, methodological and instructional issues. More specifically, she had frequent meetings with the facilitator before the beginning of the program, in order to train her in the action research methodology. Meetings took place also during and after the program to provide additional support. Furthermore, the supervisor encouraged emotionally the group of teachers with her presence in some meetings, especially when the participants were facing difficulties and were reluctant in changing their teaching practices.

\subsection{Professional Development Program in Differentiated Instruction}

The main aims of the program were to: 1) provide the appropriate context for teachers to change their ideas about DI, 2) gain deeper understanding regarding the concept of DI, the strategies and the techniques to address children's needs and 3) support effectively the teachers to apply DI activities and reflect on their action. In this scope, action research methods were leveraged to achieve the goals.

The program lasted 8 months during the academic year of 2016-2017 and included two phases: 1 ) the $1^{\text {st }}$ phase with emphasis placed on clarifying the concept of DI and gaining deeper understanding of the specific differentiated me- 
thods, strategies and techniques, and 2) the $2^{\text {nd }}$ phase during which experimentation, application and reflection on DI took place. More specifically, the goals of the $1^{\text {st }}$ phase (October-December 2016) were to deepen in DI philosophy, acquire awareness in their own teaching practices and their impact on children and compare their existing practices with the differentiated strategies. The group had 9 meetings, one per week, during which the teachers had the opportunity to express any previous experiences or/and prejudices regarding DI through various open conversations, short presentations, cooperative assignments and applied examples of differentiation in real school settings. On top of that, teachers conducted systematic observations on several aspects of children to get deeper knowledge about the exact levels of different readiness levels (literacy, mathematical and social skills), together with their interests and preferred learning styles. Their observations triggered further awareness and reflection on children's differences and their class's variations in multiple levels.

The $2^{\text {nd }}$ phase (January-May 2017) concentrated on the application of DI in participating kindergarten classrooms, aiming to provide effective support and space for reflection to teachers. During this phase teachers chose three instructional themes ("Protection of wild animals", "Healthy lifestyle", and "Books") to develop in instructional designs and then differentiate according to children's specific learning needs. The design of each theme followed the procedure: 1) division of each theme in subthemes and identification of the main learning goals by teachers and facilitator, 2) initial planning of the DI intervention by the facilitator, 3) interaction between teachers and facilitator on the initial plan, 4) final plan of DI intervention after consulting the supervisor, and 5) further adjustments of the final plan by each teacher to address sufficiently the needs of their children. During the application of the DI interventions, 8 group meetings were held every 15 days, with individual meetings in between, focusing on reflection, exchange of good practices and proposing of possible solutions in any referred problem by the group. In such cases, the teacher who referred the problem experimented with the proposed solutions back at her classroom and, then, shared her experience with the group, so that good practices emerge for the next DI intervention.

\subsection{Data Collection and Analysis}

To investigate the existing perceptions and experiences of teachers regarding DI, an open-ended questionnaire (based on Burkett, 2013) was used with 9 items. The questionnaire was divided in two sections: 1) demographic data (e.g. years of experience, degrees etc.) (4 items), and 2) perceptions and experiences (e.g. item 5. "What is your first thought when you hear the phrase 'Differentiated Instruction"” item 7. "Do you think that differentiated instruction could be applied in your classroom? Why? ').

Facilitator's notes on her diary were used as a data collection tool to evaluate the teachers' progress and, thus, inform the facilitator's further choices during the PDp. The notes were taken during the meetings and immediately after them. 
The facilitator had to record how teachers responded to their roles, their feelings, as well as her experience of her role as facilitator and her feelings.

To gain deeper understanding on how teachers experienced the entire program and their interaction with the DI practices, a semi-structured protocol for individual interviews was developed by the researchers. The protocol was based on the Guskey (2002) model of PDp's evaluation and included 10 dimensions. The interviews were conducted by the end of the program (June 2017) and lasted 50 - 120 minutes each. The analysis comprised data from the dimensions: New perceptions (5 items), Supportive role of PDp (3 items) and General evaluation (5 items).

The data analysis followed the Content Analysis methodology in a 4-step procedure: 1) read all the answers to familiarize with the data, 2) repeat in order to identify codes of similar meanings, 3 ) adjust the emerged codes, and 4) categorize the codes into broader sets. The data processing was conducted through the NVivo program for qualitative data analysis.

\section{Results}

\subsection{Initial Teachers' Perceptions of DI}

The collected answers from the teachers about their initial ideas highlighted the existence of misconceptions about the concept of differentiation. For instance, Dorothy ${ }^{1}$ referred that DI "... is an instruction that has many goals. A different goal is set for every child". Clearly, she understood DI as a way to apply individualized instruction, which is impossible to be done for all the children in a classroom. Another emerged misconception was that DI is mostly about children with difficulties, as Paola mentioned “...instruction responds to those who usually fail...". This notion implies that children have a general readiness level that is concrete, and hence, they could be categorized as low, medium and high achievers. However, DI doesn't accept the labeling of students, but recognizes that every child has different strengths and weaknesses, that are constantly changing. Additionally, the idea that DI was designed primarily for the "low achievers" puts aside the gifted learners who also suffer from "one-size-fits-all" instruction. Moreover, the high level of variations among children was sometimes seen as an obstacle rather a fertile ground for differentiation (e.g. Amy: "...I think it is applicable in my classroom, but there are too many variations in my group, differences on social and economical level").

The teacher's initial perceptions were aligned with their previous experiences of applying DI, as they rarely had tried to implement differentiation before. Even when they did, they were impermanent and superficial attempts, since "it wasn't organized but mostly random" (Paola). They usually avoided DI, because of the fear of: 1) failing in managing the classroom, 2) children not having the necessary cooperative skills and 3) failing in keeping track of students' progress. Other reasons for avoiding the differentiation were that “... the space in my classroom ${ }^{1}$ Every name is a pseudonym. 
is really tight, so its impossible to work in groups" (Stella) and the number of children per classroom, as Hannah mentioned “...there are 16 kids and I am all alone" (Figure 1).

\subsection{Formative Evaluation of PDp for DI}

Content Analysis of the diary showed that every teacher followed more or less a specific journey to professional development (Figure 2). Particularly, at the beginning of the program they were questioning not only that this program would be effective, but also that DI was not applicable in the Greek kindergarten context (e.g. record on 10/5/2016: “...she was assertive that working in groups was impossible to happen in her classroom, because it was tight. She also seemed quite skeptical if DI is just another trend that doesn't fit in the Greek reality"). After the first meetings, they started to feel nervous and sometimes denied to evaluate their children through systematic observation, seeing that it added heavy workload (e.g. record on 10/26/2016: "we talked for a while and she said she had a difficult time checking out the social skills of the kindergarteners. It took a long time for her to finish. She said exactly: I am not doing anything else!

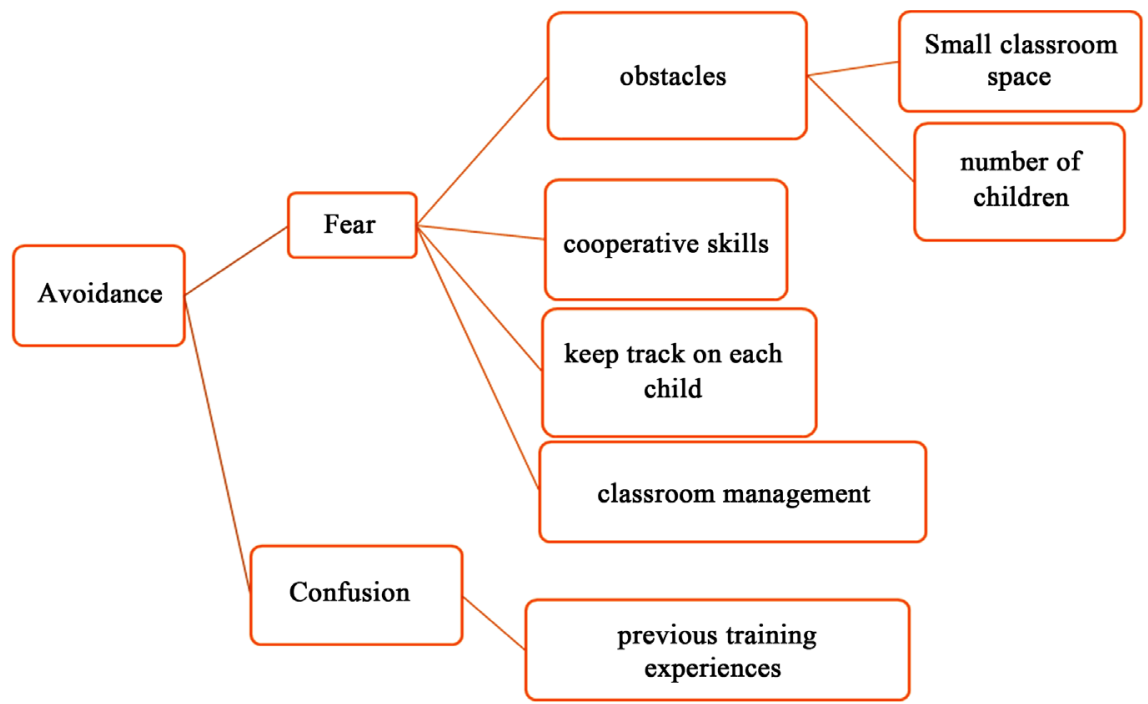

Figure 1. Reasons for teachers' avoidance to apply DI.

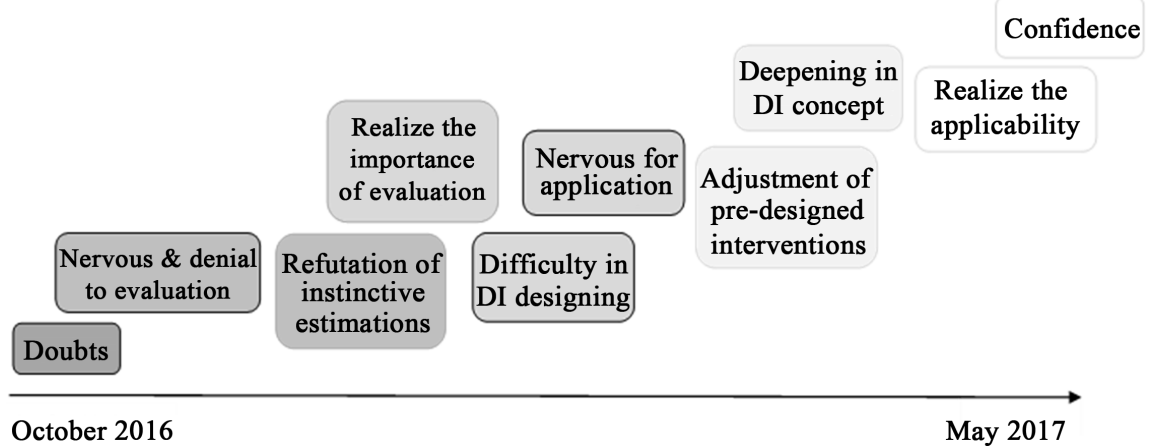

Figure 2. Teachers' progress during the PDp for DI. 
All of my teaching time is dedicated to evaluation..."). The facilitator acknowledged that the tools for systematic observations could be shorter, so a special meeting was planned to discuss and propose ways of accelerating the evaluation process. After that meeting, the teachers felt more secure to continue with the evaluation process, during which they started to realize that their instinctive estimations about children's strengths and weaknesses were often not valid. Therefore, they became more sensitive on their observations and aware of its importance (e.g. record on 11/24/2016: "Indeed, she said that this whole evaluation procedure on mathematics motivated her to find additional mathematical materials and create a new learning area in her classroom. She was thrilled and kids, too!").

Until the end of the $1^{\text {st }}$ phase, the teachers were concerned about how they would implement DI in their classrooms, although they had already participated in over 6 meetings during which they discussed thoroughly this issue. The source of their concerns laid in their insecurity to design appropriate DI interventions and then apply them. Therefore, the interventions were mainly pre-designed by the facilitator, thus helping the teachers to focus mostly on the application of the approach. Indeed, the pre-designed activities contributed to the teachers' understanding of the DI concept, as reported on 3/15/2017 "She stated she feels quite familiar with differentiation anymore, and the fact that she didn't have to design differentiated activities by her own helped her think she could accomplish to apply DI successfully...”.

Subsequently, teachers changed their initial ideas and concerns about the applicability of the approach, since they indicated the positive impact on children (e.g. record on 3/29/2017 “...(kids) remember every little detail after such a long time... things from past interventions usually appear in our group conversations at school and at home! This is something new."). The most usually referred impact that teachers reported was the autonomy level that kindergarteners achieved after the first differentiated intervention, as "the very moment they (i.e. children) see their name on the "group board", they create the groups on their own and start to cooperate without my help. I think this is huge progress" (record on 5/9/2017). The positive effects on students facilitated the teachers' self-confidence regarding the DI approach and encouraged them to continue to experiment with this approach, even after the end of the program.

\subsection{New Perceptions}

The analysis of the teachers' answers on the interviews after the PDp shed light on the new ideas that they had formed. Specifically, three categories emerged: 1) perceptions of DI, 2) perceptions of the teacher's role and 3) perceptions of teaching practices. Under the first category, teachers referred that DI was useful (4 references), applicable (3 references) and interesting (3 references), as it expanded their teaching repertoire ( 1 reference). Furthermore, the perception of their role as teachers was reinforced with confidence (5 references) and consciousness of past mistakes ( 3 references). In any case, the program led them to 
personal and professional development (6 references) (e.g. Amy "I feel I am better now. I am one step forward than I was before."). The teachers raised their awareness of the learner's differences (4 references), which led to democratization of their teaching, as "the voices of the kids are heard more often from now on. I realized they have the right to select if they want to join the activity or express themselves otherwise" (Hannah). Moreover, they changed their perceptions about the equity in education, as Hannah also pointed out "I had that misconception that it is fair for all to do the same assignments, spent the same time with me... I wasn't $t$ sure what is right or wrong... Through differentiated instruction I realized that I had to leave behind this notion. Kids didn't bother to do different assignments than their peers, because the teams, the assignments and their chance to select the assignment were not solid".

\subsection{Supportive Role of PDp}

The PDp in DI offered effective support on teachers to implement DI in their kindergarten classrooms. According to them, the PDp supported them through the meetings (19 references) and the pre-designed interventions ( 5 references). The latter was the catalyst to understand the concept of DI, since the differentiated activities were close to their experiences as practitioners. Instead of presenting DI merely on a theoretical level, the pre-designed activities offered a more practical view of the approach and facilitated the connection with their existing practice. Therefore, they argued that they “...felt much more confidence in what I am able to do when it comes to differentiation" (Stella), because the "organizing part was already done by the group" (Paola).

The meetings provided support on emotional ( 8 references) and instructional level (8 references). The positive climate at the meetings was the result of the friendly relationships that teachers grew with each other and the facilitator (1 reference). As a result, every participant felt secure, accepted, welcomed and recognized (4 references) (e.g. Nancy "The meetings took the stress away! I remember once that Paola was about to cry. I think she was relieved after the meeting... because when you hear other colleagues talking about their problems at school you know you are not alone. Everyone faces difficulties. So, the stories of others comfort you".).

On the other hand, the exchange of their experiences on DI ( 7 references) and the constant reflection on their action (3 references) administered instructional support to the teachers. Indeed, they usually mentioned how helpful their discussions about instructional and pedagogical issues were. For instance, Martha said that "It helped me a lot when those who had applied the activity a week before me shared their ideas and experience and then I knew what I should avoid or what adjustments I could probably try. Anyway, my classroom is different from the other, but I was more prepared than not having heard her experience before". And Paola also agreed "...I tried an idea that someone else from the group proposed and I had the thought "she might know better than me. Well, I wouldn't have this idea! Let's try and see if it's working with my kids, too". 


\section{Conclusion}

The PDp for DI was designed to 1) provide the appropriate context for kindergarten teachers to change their ideas about DI, 2) gain deeper understanding regarding the concept of DI, the strategies and the techniques to address children's needs and 3) support effectively the teachers to apply DI activities and reflect on their action. The results indicated that these goals were sufficiently achieved, as teachers had positive experiences with DI.

The elements of cooperation with colleagues, long-lasting duration and the chance to apply DI into a supportive context were evaluated as important factors that led to PDp's success (Hunzicker, 2011; Parsad et al., 2001; Phillips \& Weingarten, 2013; Vasumathi, 2010). Specifically, the warm relationships that occurred during the program among the participants provided a positive and supportive climate at the meetings that protected them from fears and insecurities during the application of DI, as previous research referred (Tobin \& Tippett, 2014). Although similar negative feelings were reported by the facilitator and the teachers before the application of DI, the pre-designed differentiated activities were the crucial element that encouraged them to continue with the program and start the DI application.

The systematic evaluation of children was also an issue that raised much opposition towards teachers, in alignment with other studies (Mills et al., 2014; Smit \& Humpert, 2012; Tobin \& Tippett, 2014). Seemingly, teachers need additional support with specific tools and guidelines in order to make the evaluation procedure briefer and more applicable, as it is possible that they are not quite experienced or familiar with the systematic evaluation techniques.

The misconceptions that exist before the PDp highlight the emergent need for training programs in DI, in order to facilitate the implementation of the approach (Gregory \& Chapman, 2012). The combination of the long-lasting duration with the formation of a learning community with colleagues seemed to respond to the need of the specific kindergarten teachers for definition and support (Mills et al., 2014) to make the first step towards the implementation of DI in their classroom.

However, the future application of DI by those teachers who participated in the program is not ensured, as most teachers tend to return to previous practices that feel safer and are more aligned with their perceptions and mindsets, which do not change so easily. Further research should emphasize whether teachers continue to apply DI, how the applied differentiation has changed according to teacher's personal style of teaching and what kind of support they will need, given that they will be more experienced with DI. Possible follow-back interviews may provide answers to these questions.

\section{Acknowledgements}

The research work was supported by the Hellenic Foundation for Research and Innovation (HFRI) and the General Secretariat for Research and Technology 
(GSRT), under the HFRI PhD Fellowship grant (GA. No. 2424).

\section{Conflicts of Interest}

The authors declare no conflicts of interest regarding the publication of this paper.

\section{References}

Bostina-Bratu, S., \& Negoescu, A. (2016). Differentiated Instruction in Mixed-Ability Groups: The Jigsaw Strategy. Proceedings of the 21st International Conference of the Knowledge-Based Organization, 22, 407-412. https://doi.org/10.1515/kbo-2016-0070

Brennan, S. A. (2008). Differentiated Instruction and Literacy Skill Development in the Preschool Classroom. Ph.D. Dissertation, Ames, IA: Iowa State University.

Burkett, J. A. (2013). Teacher Perception on Differentiated Instruction and Its Influence on Instructional Practice. Ph.D. Thesis, Stillwater, OK: Oklahoma State University.

Casey, M. K., \& Gable, R. K. (2012). Perceived Efficacy of Beginning Teachers to Differentiate Instruction. Proceedings of the 44th annual meeting of the New England Educational Research Association, Paper 7, 1-34.

https://scholarsarchive.jwu.edu/cgi/viewcontent.cgi?article=1006\&context=teacher_ed

Cha, H. J., \& Ahn, M. L. (2014). Development of Design Guidelines for Tools to Promote Differentiated Instruction in Classroom Teaching. Asia Pacific Education Review, 15, 511-523. https://doi.org/10.1007/s12564-014-9337-6

Chen, J., \& McCray, J. (2012). The What, How, and Why of Effective Teacher Professional Development in Early Mathematics Education. NHSA Dialog, 15, 113-121. https://doi.org/10.1080/15240754.2011.636493

Chitanana, L. (2012). A Constructivist Approach to the Design and Delivery of an Online Professional Development Course: A Case of the iEARN Online Course. International Journal of Instruction, 5, 23-48. https://eric.ed.gov/?id=ED529108

Danzi, J., Reul, K., \& Smith, R. (2008). Improving Student Motivation in Mixed Ability Classrooms Using Differentiated Instruction. Master's Dissertation, Chicago, IL: Saint Xavier University \& Pearson Achievement Solutions, Inc.

DeBaryshe, B. D., Gorecki, D. M., \& Mishima-Young, L. N. (2009). Differentiated Instruction to Support High-Risk Preschool Learners. NHSA Dialog, 12, 227-244. https://doi.org/10.1080/15240750903075305

Dweck, C. S. (2006). Mindset: The New Psychology of Success. New York: Random House.

Faber, J. M., Glas, C. A. W., \& Visscher, A. J. (2018). Differentiated Instruction in a Data-Based Decision-Making Context. School Effectiveness and School Improvement, 29, 46-63. https://doi.org/10.1080/09243453.2017.1366342

Gregory, G. H., \& Chapman, C. (2007). Differentiated Instructional Strategies. Thousand Oaks, CA: Corwin Press.

Guskey, T. R. (2002). Does It Make a Difference? Evaluating Professional Development. Educational Leadership: Journal of the Department of Supervision and Curriculum Development, 59, 45-51. https://eric.ed.gov/?id=EJ640979

Hall, T. (2002). Differentiated Instruction. Effective Classroom Practices Report. National Center on Accessing the General Curriculum. Washington DC: Office of Special Education Programs, U.S. Department of Education.

Heacox, D. (2002). Differentiating Instruction in the Regular Classroom. Minneapolis: 
Free Spirit Publishing.

Hunzicker, J. (2011). Effective Professional Development for Teachers: A Checklist. Professional Development on Education, 37, 177-179. https://doi.org/10.1080/19415257.2010.523955

Koeze, P. A. (2007). Differentiated Instruction: The Effect on Student Achievement in an Elementary School. PhD Thesis, Michigan, MI: Eastern Michigan University.

Lewis, S. G., \& Batts, K. (2005). How to Implement Differentiated Instruction? Adjust, Adjust, Adjust. Journal of Staff Development, 26, 26-31. https://eric.ed.gov/?id=EJ752247

Little, C. A., McCoach, D. B., \& Reis, S. M. (2014). Effects of Differentiated Reading Instruction on Student Achievement in Middle School. Journal of Advanced Academics, 25, 384-402. https://doi.org/10.1177/1932202X14549250

Mills, M., Monk, S., Keddie, A., Renshaw, P., Christie, P. et al. (2014). Differentiated Learning: From Policy to Classroom. Oxford Review of Education, 40, 331-348. https://doi.org/10.1080/03054985.2014.911725

Odgers, S., Symons, A., \& Mitchell, I. (2000). Differentiating the Curriculum through the Use of Problem Solving. Research in Science Education, 30, 289-300. https://doi.org/10.1007/BF02461635

Parsad, B., Lewis, L., Farris, E., \& Greene, B. (2001). Teacher Preparation and Professional Development. Washington DC: National Center for Educational Statistics US Department of Education NCES.

Phillips, V., \& Weingarten, R. (2013). The Professional Educator: Six Steps to Effective Teacher Development and Evaluation. American Educator, 37, 36-37. https://eric.ed.gov/?id=EJ1013920

Ruys, I., Defruyt, S., Rots, I., \& Aelterman, A. (2013). Differentiated Instruction in Teacher Education: A Case Study of Congruent Teaching, Teachers and Teaching. Theory and Practice, 19, 93-107. https://doi.org/10.1080/13540602.2013.744201

Santamaria, L. (2009). Culturally Responsive Differentiated Instruction: Narrowing Gaps between Best Pedagogical Practices Benefiting All Learners. Teachers College Record, 111, 214-247. https://eric.ed.gov/?id=EJ826003

Scott, B. (2012). The Effectiveness of Differentiated Instruction in the Elementary Mathematics Classroom. PhD Thesis, Muncie, IN: Ball State University.

Smit, R., \& Humpert, W. (2012). Differentiated Instruction in Small Schools. Teaching and Teacher Education, 28, 1152-1162. https://doi.org/10.1016/j.tate.2012.07.003

Suprayogi, M. N., Vackle, M., \& Godwin, R. (2017). Teachers and Their Implementation of Differentiated Instruction in the Classroom. Teaching and Teacher Education, 67, 291-301. https://doi.org/10.1016/j.tate.2017.06.020

Taylor, B. K. (2015). Content, Process, and Product: Modeling Differentiated Instruction. Kappa Delta Pi Record, 51, 13-17. https://doi.org/10.1080/00228958.2015.988559

Tieso, C. (2005). The Effects of Grouping Practices and Curricular Adjustments on Achievement. Journal for the Education of the Gifted, 29, 60-89.

https://doi.org/10.1177/016235320502900104

Timperley, H. (2008). Using Evidence in the Classroom for Professional Learning. Paper Presented to the Ontario Education Research Symposium.

http://www.educationalleaders.govt.nz/Leading-learning/Professional-learning/Using-e vidence-in-the-classroom-for-professional-learning

Tobin, R., \& McInnes, A. (2008). Accommodating Differences: Variations in Differentiated Literacy Instruction in Grade 2/3 Classrooms. Literacy, 42, 3-9. 
https://doi.org/10.1111/j.1467-9345.2008.00470.x

Tobin, R., \& Tippett, C. D. (2014). Possibilities and Potential Barriers: Learning to Plan for Differentiated Instruction in Elementary Science. International Journal of Science and Mathematics Education, 12, 423-443. https://doi.org/10.1007/s10763-013-9414-Z

Tomlinson, C. A. (1999). The Differentiated Classroom: Responding to the Needs of All Learners. Alexandria, VA: Association for Supervision and Curriculum Development.

Tomlinson, C. A. (2001). How to Differentiate Instruction in Mixed-Ability Classrooms. Upper Saddle River, NJ: Pearson Education.

Tomlinson, C. A., \& McTighe, J. (2004). Integrating Differentiated Instruction and Understanding by Design: Connecting Content and Kids. Alexandria, VA: Association for Supervision and Curriculum Development.

Tomlinson, C. A., \& Moon, T. R. (2013). Assessment and Student Success in a Differentiated Classroom. Alexandria, VA: Association for Supervision and Curriculum Development.

Tomlinson, C. A., Brighton, C., Hertbert, H., Callahan, C. M., Moon, T. R., Brimijoin, K. et al. (2003). Differentiating Instruction in Response to Student Readiness, Interest, and Learning Profile in Academically Diverse Classrooms: A Review of Literature. Journal for the Education of the Gifted, 27, 119-145. https://doi.org/10.1177/016235320302700203

Vasumathi, T. (2010). A Design for Professional Development of Teachers-Need for New Policy Framework. https://eric.ed.gov/?id=ED512828

Wan, S. W.-Y. (2017). Differentiated Instruction: Are Hong Kong In-Service Teachers Ready? Teachers and Teaching, 23, 284-311.

Watts-Taffe, S., Laster, B. P., Broach, L, Marinak, B., McDonald-Connor, C., \& Walker-Dalhouse, D. (2012). Differentiated Instruction: Making Informed Teacher Decisions. The Reading Teacher, 66, 303-314. https://doi.org/10.1002/TRTR.01126

Wu, S.-C., \& Chang, Y.-L. (2015). Advancing Kindergarten Teachers' Knowledge and Capabilities of Differentiated Instruction Associated with Implementation of Thematic Integrated Curriculum. Procedia-Social and Behavioral Sciences, 177, 246-250. 